CNS Spectrums (2013), 18, 322-332. (c) CNS 2013. The online version of this article is published within an Open Access environment subject to the conditions of the Creative Commons

Attribution-NonCommercialShareAlike licence, http://creativecommons.org/licenses/by-nc-sa/3.0/.

The written permission of Cambridge University Press must be obtained for commercial re-use doi:10.1017/S1092852913000357

\title{
Transcranial magnetic stimulation (TMS) for major depression: a multisite, naturalistic, observational study of quality of life outcome measures in clinical practice
}

\author{
Philip G. Janicak, ${ }^{1 *}$ David L. Dunner, ${ }^{2}$ Scott T. Aaronson, ${ }^{3}$ Linda L. Carpenter, ${ }^{4}$ \\ Terrence A. Boyadjis, ${ }^{5}$ David G. Brock, ${ }^{6}$ Ian A. Cook, ${ }^{7}$ Karl Lanocha, ${ }^{8}$ Hugh B. Solvason, ${ }^{9}$ \\ Dafna Bonneh-Barkay, ${ }^{6}$ and Mark A. Demitrack ${ }^{6}$ \\ ${ }^{1}$ Psychiatric Clinical Research Center and Transcranial Magnetic Stimulation Center, Rush University, Chicago, Illinois, USA \\ ${ }^{2}$ Center for Anxiety and Depression, Mercer Island, Washington, USA; University of Washington, Seattle, Washington, USA \\ ${ }^{3}$ Clinical Research Programs and TMS Services, Sheppard-Pratt Health System, Baltimore, Maryland, USA \\ ${ }^{4}$ Brown Department of Psychiatry and Human Behavior, Brown University; Butler Hospital Mood Disorders Program, Providence, Rhode Island, USA \\ ${ }^{5}$ Private Practice, West Chester, Pennsylvania, USA \\ ${ }^{6}$ Medical Operations, Neuronetics, Inc., Malvern, Pennsylvania, USA \\ ${ }^{7}$ UCLA Depression Research and Clinic Program, UCLA School of Medicine; Department of Psychiatry and Biobehavioral Sciences, Semel Institute for \\ Neuroscience and Human Behavior at UCLA, Los Angeles, California, USA \\ ${ }^{8}$ TMS Center of New England, Portsmouth, New Hampshire, USA \\ ${ }^{9}$ Department of Psychiatry, Stanford University Medical Center, Palo Alto, California, USA
}

Background. Transcranial magnetic stimulation (TMS) is an effective and safe therapy for major depressive disorder (MDD). This study assessed quality of life (QOL) and functional status outcomes for depressed patients after an acute course of TMS.

Methods. Forty-two, U.S.-based, clinical TMS practice sites treated 307 outpatients with a primary diagnosis of MDD and persistent symptoms despite prior adequate antidepressant pharmacotherapy. Treatment parameters were based on individual clinical considerations and followed the labeled procedures for use of the approved TMS device. Patient self-reported QOL outcomes included change in the Medical Outcomes Study 36-Item Short-Form Health Survey (SF-36) and the EuroQol 5-Dimensions (EQ-5D) ratings from baseline to end of the acute treatment phase.

Results. Statistically significant improvement in functional status on a broad range of mental health and physical health domains was observed on the SF-36 following acute TMS treatment. Similarly, statistically significant improvement in patient-reported QOL was observed on all domains of the EQ-5D and on the General Health Perception and Health Index scores. Improvement on these measures was observed across the entire range of baseline depression symptom severity.

Conclusion. These data confirm that TMS is effective in the acute treatment of MDD in routine clinical practice settings. This symptom benefit is accompanied by statistically and clinically meaningful improvements in patient-reported QOL and functional status outcomes.

Received 13 February 2013; Accepted 8 April 2013; First published online 30 July 2013

Key words: Clinical trial, depression, functional status, quality of life, transcranial magnetic stimulation.

\footnotetext{
*Address correspondence to: Philip G. Janicak, MD, Rush University Medical Center, Psychiatric Clinical Research Center, 2150 West Harrison Street, Room 253, Chicago, IL 60612, USA.

(Email: pjanicak@rush.edu)

This research was supported by a grant from Neuronetics, Inc. The clinical trial was posted on http://www.clinicaltrials.gov, listing number NCT 01114477 . We would like to thank the NeuroStar TMS Therapy Outcomes Study Group for their contributions to this report. We would also like to thank Seth Zuckerman, MS, for his assistance as an independent consultant with the statistical analyses in this report.
}

\section{Introduction}

Major depressive disorder (MDD) is a debilitating and often chronic disease. By 2020, it is projected to be the second leading cause of disability based on disability-adjusted life-years (DALYs). ${ }^{1}$ In addition, MDD is considered one of the primary causes of disease burden in developed nations, as it is associated with increases in both healthcare service utilization and in public health costs. ${ }^{2,3}$ 
Although a range of antidepressant medications are available for the treatment of MDD, nearly two-thirds of patients do not benefit adequately from an initial course of pharmacotherapy, and continue to be symptomatic and functionally impaired. ${ }^{4,5}$ Current practice guideline recommendations in the setting of initial treatment resistance involve sequential, empirical attempts usually involving progressively more complex forms of medication therapy. For example, medication switches within or between classes; antidepressant combinations; or adjunctive therapy with lithium, thyroid hormone, mood stabilizers, or second-generation antipsychotics are commonly recommended. ${ }^{6}$ Most of these clinically accepted approaches involve strategies that have not received specific regulatory approval for use in the setting of initial pharmacoresistance. Further complicating clinical management is evidence that the likelihood of achieving remission progressively diminishes with each failed treatment attempt. The Sequenced Treatment Alternatives to Relieve Depression (STAR*D) Study demonstrated that despite best efforts, approximately one-third of patients will remain refractory to pharmacotherapy following four sequential courses of medication at an adequate dose and duration. ${ }^{7-14}$

Transcranial magnetic stimulation (TMS) is a safe and effective treatment option, specifically for patients with MDD who fail to benefit from initial pharmacotherapy. ${ }^{15-20}$ The evidence from these randomized controlled trials is recently supported by two large, naturalistic observational studies of TMS in clinical practice settings. ${ }^{21,22}$ TMS uses pulsed, MRI-strength magnetic fields to induce electrical currents in the cortex of the brain. These induced currents directly cause neuronal depolarization in local targeted brain regions and indirectly affect more distant regions that are anatomically connected. The result is therapeutically beneficial modulation of the neural circuitry implicated in the pathophysiology of depression. ${ }^{23,24}$

By design, clinical trials of antidepressant treatments focus on establishing efficacy for specific, symptomatic measures of change, usually involving well-validated clinician and patient-rated illness scales. Recent work focuses attention on the observation that despite clear evidence of symptomatic benefit, many patients experience substantial levels of social and occupational impairment, comparable to the level of disability seen in other serious, chronic medical conditions. ${ }^{25}$ Further, this impairment in function and quality of life (QOL) tends to persist even after symptomatic remission. ${ }^{25-27}$ Thus, outcome measures of QOL are increasingly used in clinical trials to assess well-being across several domains of psychosocial functionality. ${ }^{28-30}$ This is important since disease-specific measures of illness severity may not accurately describe the overall benefit of a treatment. ${ }^{31}$ For example, while medication may improve depressive symptoms, it may also induce unpleasant side effects that impair the patient's perceived QOL. ${ }^{32}$ Further, McCall et al. ${ }^{33}$ reported that maximal improvement in QOL may lag weeks or months behind maximum symptom improvement. Thus, a patient's perception of health and well-being does not always correlate with improvement in symptoms alone, but results from a complex interaction between various disease- and treatment-specific contextual factors. Understanding QOL and functional outcomes is critically important in predicting long-term treatment success. For example, psychosocial impairment is associated with a decreased probability of full recovery from a major depressive episode (MDE). ${ }^{34}$

Patient-reported measures of QOL, such as the Medical Outcomes Study 36-Item Short-Form Health Survey (SF-36) and the EuroQol 5-Dimensions (EQ-5D), are well-validated and assess functional status and life quality in various health-related, social, and occupational domains. ${ }^{35,36}$ Previous studies found that these instruments are sensitive to change and correlate with clinical improvements in depression. ${ }^{37}$

In this multisite, naturalistic, observational study, we examined the effect of TMS on these self-report measures of QOL and functional status in patients with pharmacoresistant MDD. We also examined the relationship between changes in these outcomes with changes in depressive symptoms. Because previous studies found that TMS is devoid of systemic adverse effects and has a low incidence of discontinuation, we hypothesized that clinically meaningful changes in patient-reported QOL outcomes could occur early in treatment.

\section{Methods}

\section{Study overview and study population}

A complete description of the study design, methods, and patient disposition are reported elsewhere. ${ }^{21}$ Briefly, this was a naturalistic observational study conducted at 42 clinical practice locations in the United States: $32(76 \%)$ private clinical practices, $7(17 \%)$ academic medical centers, and $3(7 \%)$ non-academic institutions. Patients were eligible to participate and were considered evaluable for the study data analysis if (1) their primary clinical diagnosis was a MDE [single or recurrent without psychotic features, consistent with Diagnostic and Statistical Manual of Mental Disorders, 4th edition (DSM-IV) criteria]; (2) they did not have medical conditions that precluded the safe use of TMS therapy; (3) they had not received past treatment with TMS for depression; (4) they met standardized criteria for failure to receive clinical benefit from antidepressant medication treatment in the current illness episode; (5) they had 
a baseline and at least one post-baseline rating; (6) their attending psychiatrist determined that TMS represented the most appropriate clinical treatment option; and (7) the attending psychiatrist initiated treatment using the currently labeled TMS parameters. The methods and instruments used to assess symptomatic change in depression and the outcomes of these measures across acute treatment with TMS in routine clinical practice were previously reported. ${ }^{21}$ The purpose of the current report is to provide a comprehensive description of additional patient-reported QOL and functional status outcome measures obtained during acute treatment in the evaluable study population. The number of patients who met these a priori-defined evaluable criteria at baseline was 307 , and 286 provided at least 1 post-baseline observation for either the SF-36 or EQ-5D assessments.

There was no limit on the number of lifetime antidepressant treatment failures in study participants. Treatment resistance was determined with the Antidepressant Treatment Record (ATR; Neuronetics, Inc., Malvern, PA, USA). The ATR is a clinician-administered antidepressant treatment history inventory adapted from and validated against the research version of the Antidepressant Treatment History Form (ATHF). ${ }^{4}$ This naturalistic study design permitted patients to continue concurrent psychiatric medications during treatment with TMS if directed by their prescribing psychiatrist. Decisions to administer TMS adjunctively reflected a determination that these agents could not be safely discontinued [300 of $307(97.7 \%)$ of patients were taking one or more psychotropic medications at study baseline].

Institutional review board (IRB) approval was obtained at all participating sites. After a complete description of the study, written informed consent was obtained from all subjects prior to any study-related procedures.

\section{TMS device and clinical treatment parameters}

All treatments were delivered using the NeuroStar TMS Therapy system (Neuronetics, Inc.). Motor threshold (MT) was determined over the left hemisphere at the initial session and used for determination of treatment intensity. An iterative, automated software-based mathematical algorithm (MT Assist, Neuronetics, Inc.) is integrated with this system for use in MT determination. External coordinates for placement of the coil over the treatment location are calculated by the device for a site $5 \mathrm{~cm}$ anterior from the MT location, along a left superior oblique plane. The standard treatment protocol described in the product user manual specifies stimulation at $120 \%$ of MT, pulse frequency of 10 pulses per second, and a cycle of 4 seconds on (active stimulation) and 26 seconds off (no stimulation). This system provides default parameters that generate 75 stimulation cycles, resulting in 3000 pulses per treatment session. While all clinicians initiated treatment with left-sided, high frequency stimulation, the treatment protocol could be modified for tolerability or logistical reasons, or as a consequence of clinician-determined variation in practice technique. Two hundred eighty (91.2\%) patients received standard labeled treatment over the left dorsolateral prefrontal cortex only. The proportion of patients treated with variations in technique beyond the standard labeled treatment protocol was too few to provide meaningful comment on any potential differences in clinical outcome for this subset of patients (data not shown).

\section{Functional status and quality of life outcome measures}

Patient-reported outcome measures of functional status and QOL were obtained at baseline prior to the initial TMS treatment, and again at the end of acute treatment.

Functional status was ascertained using the Medical Outcome Study Short-Form Health Survey, (SF-36) version 1 . This well-validated, self-administered questionnaire measures functional health status and is a criterion standard for health-related QOL. ${ }^{38}$ It contains 8 subscales that measure physical and role functioning, bodily pain, general health, vitality, social and role functioning, and mental health. Higher scores on each scale indicate better functioning in the specific domain. The 8 subscales form 2 distinct higher-ordered clusters of physical and mental health. The physical component summary (PCS) score and mental component summary (MCS) score integrate information from all 8 of the domain subscales. The PCS and MCS are adjusted by the population mean and standard deviation to produce norm-based scores with a common mean of 50 and standard deviation of 10 . Thus, any score $<50$ represents a decrement from "normal" health and functioning.

Patient-reported QOL was characterized using the EuroQol 5-Dimension Questionnaire (EQ-5D). This wellvalidated, self-administered questionnaire measures functional health status and is a criterion standard for health-related QOL. ${ }^{39}$ It contains 5 dimensions measuring the degree of impairment in the domains of mobility, self-care, usual activities, pain/discomfort, and anxiety/ depression. Each dimension has 3 levels: no problems, some problems, or extreme problems; the patient is asked to indicate his or her health status in the specific domain. The EQ-5D also uses a visual analog scale to assess a patient's General Health Perception, with endpoints anchored at the "best imaginable health state" and the "worst imaginable health state."

The EQ-5D also computes a composite Health Index score derived from the scoring obtained on the 5 health 
dimensions, and incorporating the U.S. populationbased preference weights as published on the Agency for Healthcare Research and Quality Web site For the U.S. general population ${ }^{40}$, the possible EQ-5D Health Index scores range from -0.11 to 1.0 on a scale where $0.0=$ death and $1.0=$ perfect health (note that the EQ-5D is capable of characterizing outcomes that may be perceived by the patient as resulting in a QOL measure of "worse than death"). ${ }^{41}$

\section{Statistical analysis}

For continuous variables, within-group testing comparing the baseline and the end of acute treatment observation time points was performed using the Student's t-test for normally distributed data and the Wilcoxon Signed Rank test for non-normally distributed data. Normality testing was evaluated using the ShapiroWilk statistic. Categorical variables were tested using a chi-square analysis. All tests were two-sided, at the $5 \%$ level of statistical significance. Results are reported at the 2 observation time points of baseline and end of acute treatment. Because the overall discontinuation rate was less than $15 \%$, nearly all patients who entered acute treatment provided information at both observations. Therefore, an observed case analysis (including all available data) on the intent-to-treat population was used as the primary analysis set.

A number of secondary analyses were also conducted. First, we compared the relationship between the magnitude of change in functional status or QOL to the magnitude of the change in depression symptom scores to assess the level of impairment in those patients who received the most complete symptomatic benefit from treatment. To accomplish this, betweengroup comparisons were performed on end of acute treatment clinician-rated remission versus non-remission population subgroups. For purposes of this analysis, clinician-rated remission was defined using the Clinician Global Impressions-Severity of Illness Scale (CGI-S) as in the original depression symptom efficacy outcomes reported from this study. ${ }^{21}$ In that analysis, remission was defined as an end of acute treatment CGI-S score of 1 or 2 .

Second, to determine whether the improvement in functional status or QOL was evident across the full range of symptom distress, we examined the baseline to end of acute treatment change in the two SF-36 component scores (PCS and MCS) and in the EQ-5D Health Index score in subgroups stratified based on their baseline Patient Health Questionnaire (PHQ-9) total score (see Figure 1 for definition of category groupings). We chose the PHQ-9 as the method of baseline symptom stratification in this analysis because it has the least variance among the measures, and published literature exists defining these symptom severity groupings for the PHQ-9. ${ }^{42}$ Finally, because there are several clinical variables that may influence a patient's response to treatment, we performed a secondary analysis to determine potential predictors of improvement in functional status and QOL outcome with TMS treatment. ${ }^{43,44}$ The candidate pre-treatment variables and their method of stratification included the following: gender $(\mathrm{M} / \mathrm{F})$, age (age $\leq 55$ years vs $>55$ years), employment status (employed full time, part-time, or unemployed), salary ( $<\$ 50,000$ vs $\geq \$ 50,000)$, the presence of a secondary anxiety disorder diagnosis $(\mathrm{Y} / \mathrm{N})$, ATR status at baseline (baseline ATR $\leq 1$ vs $\geq 2$ ), and depression symptom severity at baseline (as a continuous variable measured by the CGI-S, PHQ-9, and IDS-SR). We screened these candidate variables following a methodological framework described in our previous report. ${ }^{21}$ In that method, we used an analysis of variance model to explore the candidate predictors, with the criterion that a potentially significant moderating variable should demonstrate a main effect at a $\mathrm{P}<0.10$, and its influence on outcome should be evident at this level of statistical strength across the three main composite indices of functional status and QOL improvement (ie, the SF-36 component scores, PCS and MCS, and the EQ-5D Health Index score).

\section{Results}

\section{Demographic and clinical characteristics}

Demographic and clinical characteristics of the study population are shown in Table 1. A recurrent course of illness was reported in $93 \%$ of patients, and $44 \%$ had previously been hospitalized for depression. A significant level of treatment resistance was present, with over half of the population meeting ATR criteria for failure to benefit from two or more antidepressant trials of adequate dose and duration during the current episode. Baseline measures of functional status and QOL were significantly impaired. For example, the SF-36 MCS score at baseline was more than 2 standard deviations below the norm-based reference population standardized mean score. ${ }^{45}$ Baseline measures of symptom severity were consistent with a moderate to severe degree of depression prior to treatment.

\section{Patient-reported functional status and $Q O L$ outcomes}

\section{SF-36-subscale scores and component scores}

Subscale scores on the SF-36 at baseline and at the end of acute TMS treatment are summarized in Table 2. The largest treatment effects were observed on those 
Table 1. Demographic and clinical characteristics of study population $(N=307)$

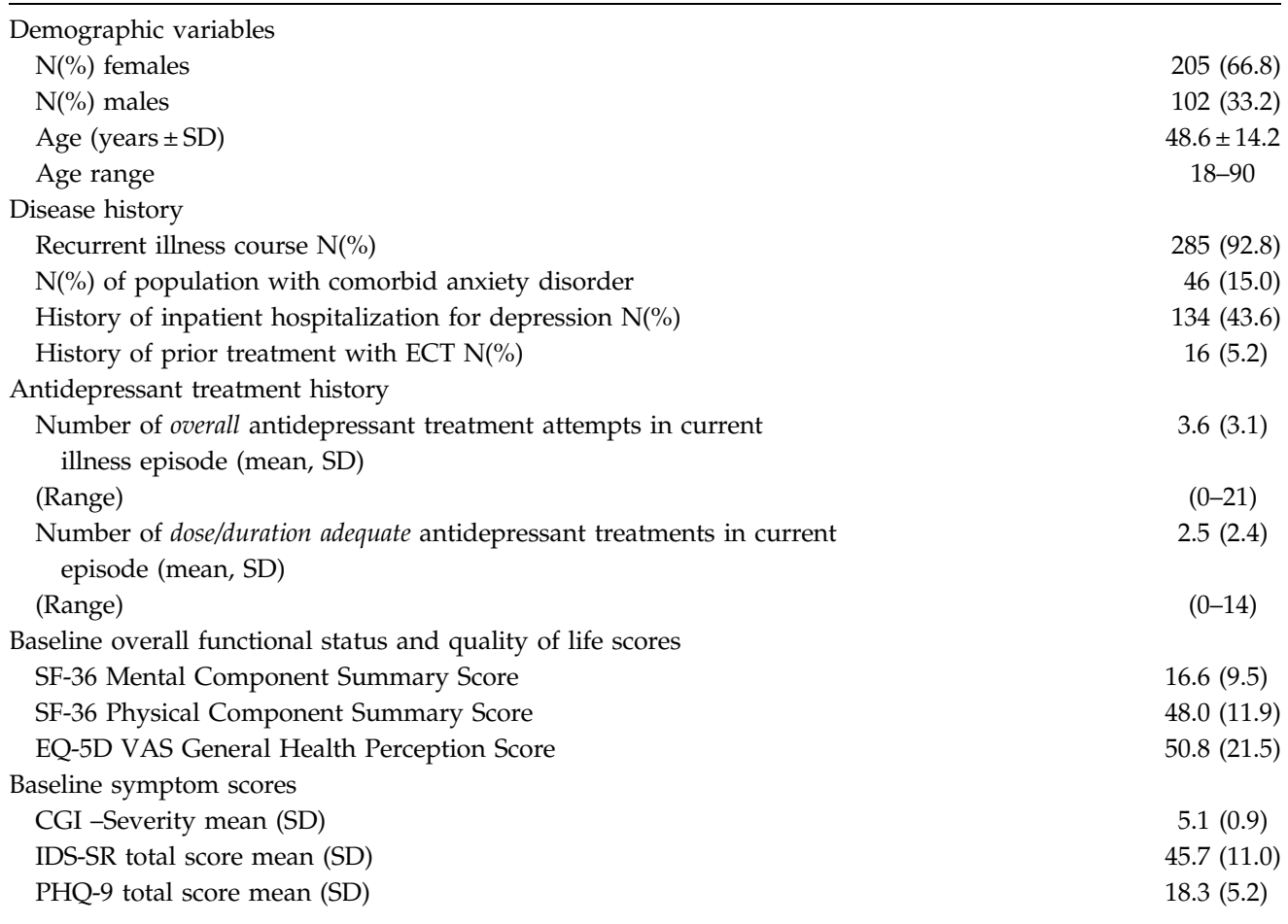

Table 2. SF-36 subscale and component score outcomes during acute TMS treatment $(N=307)$

\begin{tabular}{lcc}
\hline SF-36 clinical rating & Baseline & End of acute treatment \\
\hline Subscale Scores & & \\
Physical Function mean (SD) & $42.4(11.6)$ & $47.6(11.0)$ \\
P-value & & $<\mathbf{0 . 0 0 0 1}$ \\
Role Physical mean (SD) & $34.8(12.8)$ & $42.0(12.1)$ \\
P-value & & $<\mathbf{0 . 0 0 0 1}$ \\
Bodily Pain mean (SD) & $44.2(11.5)$ & $48.0(11.6)$ \\
P-value & & $<\mathbf{0 . 0 0 0 1}$ \\
General Health mean (SD) & $38.1(11.0)$ & $44.1(11.4)$ \\
P-value & & $<\mathbf{0 . 0 0 0 1}$ \\
Vitality mean (SD) & $29.7(7.7)$ & $41.7(12.4)$ \\
P-value & & $<\mathbf{0 . 0 0 0 1}$ \\
Social Functioning mean (SD) & $23.8(9.4)$ & $35.9(12.7)$ \\
P-value & & $<\mathbf{0 . 0 0 0 1}$ \\
Role Emotional mean (SD) & $21.1(10.1)$ & $34.4(13.9)$ \\
P-value & & $<\mathbf{0 . 0 0 0 1}$ \\
Mental Health mean (SD) & $22.4(8.7)$ & $37.2(13.7)$ \\
P-value & & $<\mathbf{0 . 0 0 0 1}$ \\
Component Scores & & $49.9(10.4)$ \\
PCS mean (SD) & $48.0(11.9)$ & $\mathbf{0 . 0 1 3 2}$ \\
P-value & & $33.5(15.1)$ \\
MCS mean (SD) & $16.6(9.5)$ & $<\mathbf{0 . 0 0 0 1}$ \\
P-value & & \\
& & \\
\end{tabular}

Notes: All data were computed using an observed case analysis.

P-value reflects within-group comparison of change from baseline to end of treatment performed using Student's T-Test.

MCS $=$ Mental Component Summary score, $\mathrm{PCS}=$ Physical Component Summary score. 

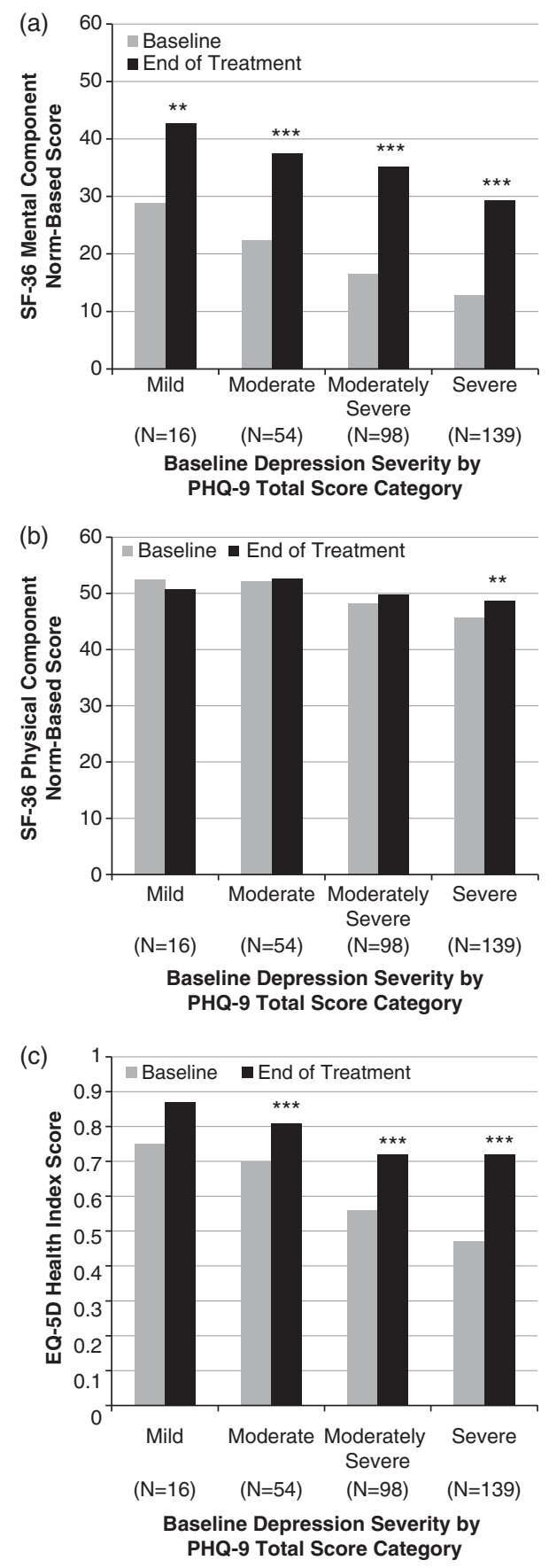

Figure 1. SF-36 Mental Component and Physical Component Scores, EQ-5D Health Index Score: outcome stratified by baseline patient-reported depression symptom severity. Notes: All data were computed using an observed case analysis. Mild Depression $=$ PHQ- 9 total score $<10$; Moderate Depression $=$ PHQ-9 total score 11 to 15 ; Moderately Severe Depression $=$ PHQ-9 total score 16 to 20; Severe Depression $=$ PHQ-9 total score $>20$. Within-group comparison of change from baseline to end of treatment performed using Student's T-Test: ${ }^{*}=\mathrm{P}<0.01,{ }^{*}=\mathrm{P}<0.001$, $* * *=\mathrm{P}<0.0001$. Overall analysis of variance model showed no statistically significant differences in the change from baseline score between the PHQ-9 Depression Severity categories. subscale scores associated with improvements in mental health and social functioning (ie, vitality, social functioning, role emotional, and mental health subscales). A correspondingly larger improvement was observed in the MCS score versus PCS score.

As reported elsewhere, $37.1 \%(\mathrm{~N}=114)$ of the evaluable population achieved remission as defined by a clinician-rated end of acute treatment CGI-S score of $\leq 2 .{ }^{21}$ This patient group showed a significantly greater improvement in MCS scores at the end of acute treatment [ie, a mean increase of 27.4 points (95\% CI: 24.9-29.9)], compared with those patients who did not reach remission during acute TMS treatment [ie, a mean increase of 9.6 points $(95 \% \mathrm{CI}$ : 7.9-11.4)]. This same pattern of mental health improvement was evident when patient-reported outcomes (ie, PHQ-9 and IDS-SR) were used to define remission outcome. Patients who achieved remission on either the IDS-SR (defined as a total score $<15$ ) or the PHQ-9 (defined as a total score $<5$ ) showed a significantly greater improvement in MCS scores at the end of acute treatment compared with those patients who did not reach remission during acute TMS treatment [ie, for the IDS-SR: remitters showed a mean increase of 30.9 points (95\% CI: $28.0-33.9$ ) vs non-remitters who showed a mean increase of 11.1 points $(95 \%$ CI: 9.4-12.7); the PHQ-9: remitters showed a mean increase of 30.1 points (95\% CI: $27.3-32.8$ ) vs nonremitters who showed a mean increase of 9.8 points (95\% CI: 8.0-11.6)].

Finally, improvement in the SF-36 MCS and PCS scores in the study population was consistent across the range of depression symptom severity when grouped by baseline PHQ-9 total scores (Figures 1A-1C).

\section{EQ-5D-Health Profile Summary scores, VAS General Health Perception, and Health Index scores}

EQ-5D Health Profile Summary domain scores, VAS General Health Perception, and Health Index scores are summarized in Table 3. The largest treatment effects were observed on the domain scores associated with improvements in mental health (ie, anxiety/ depression). Notably, statistically significant improvements in health function were seen in all domains, with the second largest treatment effects observed in the ability to carry out usual daily activities. Corresponding and statistically significant improvements were also seen in the General Health Perception and Health Index scores (Table 3).

Using the same categorical end of treatment grouping of remission based on CGI-S total score noted above (CGI-S $\leq 2$ ), the remitted patient group showed a significantly greater improvement in the Health Index score [ie, 0.26 points (95\% CI: $0.22-0.29)$ ] 
Table 3. Summary of baseline and end of acute treatment EQ-5D scores: Health Profile Summary, VAS General Health Perception score, and Health Index Score $(N=307)$

\begin{tabular}{|c|c|c|}
\hline EQ-5D clinical rating & Baseline & End of acute treatment \\
\hline \multicolumn{3}{|l|}{ Health Profile Summary scores } \\
\hline \multicolumn{3}{|l|}{ Mobility } \\
\hline No problems N(\%) & $211(68.7)$ & $234(81.8)$ \\
\hline Some problems $\mathrm{N}(\%)$ & $92(30.0)$ & $51(17.8)$ \\
\hline Extreme problems $\mathrm{N}(\%)$ & $4(1.3)$ & $1(0.3)$ \\
\hline P-value1 & & $<0.0003$ \\
\hline \multicolumn{3}{|l|}{ Self Care } \\
\hline No problems N(\%) & $223(72.6)$ & $249(87.1)$ \\
\hline Some problems $\mathrm{N}(\%)$ & $83(27.0)$ & $36(12.6)$ \\
\hline Extreme problems $\mathrm{N}(\%)$ & $1(0.3)$ & $1(0.3)$ \\
\hline P-value1 & & $<0.0001$ \\
\hline \multicolumn{3}{|l|}{ Usual Activities } \\
\hline No problems N(\%) & $44(14.3)$ & $129(45.1)$ \\
\hline Some problems $\mathrm{N}(\%)$ & $210(68.4)$ & $138(48.3)$ \\
\hline Extreme problems $\mathrm{N}(\%)$ & $53(17.3)$ & $19(6.6)$ \\
\hline P-value1 & & $<0.0001$ \\
\hline \multicolumn{3}{|l|}{ Pain/Discomfort } \\
\hline No problems N(\%) & $121(39.4)$ & $151(52.8)$ \\
\hline Some problems $\mathrm{N}(\%)$ & $153(49.8)$ & $117(40.9)$ \\
\hline Extreme problems $\mathrm{N}(\%)$ & $33(10.7)$ & $18(6.3)$ \\
\hline P-value1 & & $<0.0017$ \\
\hline \multicolumn{3}{|l|}{ Anxiety/Depression } \\
\hline No problems N(\%) & $5(1.6)$ & $86(30.1)$ \\
\hline Some problems $\mathrm{N}(\%)$ & $110(35.8)$ & $142(49.7)$ \\
\hline Extreme problems $\mathrm{N}(\%)$ & $192(62.5)$ & $58(20.3)$ \\
\hline P-value1 & & $<0.0001$ \\
\hline \multicolumn{3}{|c|}{ VAS General Health Perception Score } \\
\hline Mean (SD) & $50.8(21.5)$ & $67.7(21.3)$ \\
\hline P-value2 & & $<0.0001$ \\
\hline \multicolumn{3}{|l|}{ Health Index Score } \\
\hline Mean (SD) & $0.56(0.2)$ & $0.75(0.2)$ \\
\hline P-value2 & & $<0.0001$ \\
\hline
\end{tabular}

Notes: All data were computed using an observed case analysis.

P-value1 reflects the comparison of the proportion of patients reporting No Problems (Level 1) with the proportion of patients reporting Some or Extreme Problems (Levels 2 and 3 combined) from the baseline to end of treatment observation time points using a chi-square test.

P-value2 reflects within group comparison of change from baseline to end of treatment performed using Student's T-Test.

compared to the non-remitter group [ie, 0.13 points (95\% CI: $0.10-0.17)]$. This same pattern of improvement was evident when patient-reported outcomes were used to define remission outcome. Patients who achieved remission on either the IDS-SR (defined as a total score $<15$ ) or the PHQ-9 (defined as a total score $<5$ ) showed a significantly greater improvement in Health Index scores at the end of acute treatment compared with those patients who did not reach remission during acute TMS treatment [ie, the IDS-SR: remitters showed a mean increase of 0.28 points $(95 \%$ CI: $0.24-0.32)$, vs non-remitters who showed a mean increase of 0.14 points (95\% CI: $0.11-0.17$ ); the PHQ-9: remitters showed a mean increase of 0.27 points (95\% CI: $0.23-0.31$ ), vs. non-remitters who showed a mean increase of 0.13 points (95\% CI: $0.10-0.16)$ ].

Finally, improvement in the Health Index score was consistent across the range of depression symptom severity in the population when grouped by baseline PHQ-9 total scores (Figures 1A-1C).

\section{Influence of pre-treatment candidate predictors on QOL outcome measures}

In the overall study population, none of the pretreatment predictors of outcome met the defined 
criterion standard showing a significant main effect on outcome (data not shown). It is worth noting that ATR status had no effect on treatment outcome measures of functional status or QOL.

\section{Discussion}

Despite a variety of treatment options available for depression, recent studies find that pharmacoresistant patients continue to experience symptomatic and functional disability. ${ }^{31,46}$ This study explored the effect of an acute trial of TMS on health-related QOL outcomes in patients with treatment-resistant depression seen in clinical practice settings. To assess improvement in functional disability, we used the SF-36 and EQ-5D measures of QOL. These measures capture improvement in the health of depressed patients and differentiate between severity subgroups. ${ }^{37,47,48}$ Our findings indicate that the amelioration of depressive symptoms is accompanied by an improvement in QOL. Both SF-36 and EQ-5D measures showed that remitted patients experienced a superior improvement in QOL compared with nonremitters, and patients with moderately severe to severe depression had the most robust improvement in QOL. In addition, our results suggest that TMS treatment has a relatively rapid beneficial impact on the QOL in these patients.

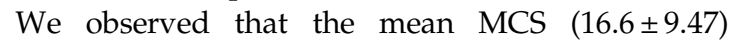
baseline score was more than 3 SDs below general population norms. This was slightly below the SF-36 MCS reported in other studies (ie, 2-3 SDs below norms). ${ }^{45,49,50}$ In contrast, the mean PCS baseline score $(48 \pm 11.91)$ was similar to the general population.

Similar to earlier antidepressant medication studies, improvements were much greater for mental health than for physical health dimensions. ${ }^{45,49,51,52}$ The vitality, social functioning, role-emotional, and mental health perceptions subscales all showed a statistically significant improvement of 1.2-1.5 SDs. The mean MCS score improved by 16.8 points to $33.5( \pm 15.06)$, which is comparable to previous studies showing an improvement in the MCS scores following 9 months of treatment with paroxetine (15.8), fluoxetine (15.1), or sertraline (17.4). ${ }^{53}$ The subpopulation of remitters showed a much more robust improvement of 27.4 to 30.9 points, reaching scores that are close to the general population norms and are only 0.13 to 0.55 SDs lower. In contrast, non-remitters showed only modest improvements of 9.6 to 11.1 points. While the Factors Influencing Depression Endpoints Research (FINDER) Study (a European, prospective, observational trial in 3,468 patients) reported that severely depressed patients had significantly worse SF-36 MCS outcomes, we observed that acute TMS treatment produced a pronounced QOL improvement in moderately severely and severely-ill patients compared with the mildly and moderately-ill subgroups. ${ }^{52}$ At the end of acute treatment, the physical functioning, role-physical, bodily pain, and general health perceptions subscales all showed statistically significant but modest improvement (range from $0.38-0.72$ SDs relative to the population norms), whereas the PCS score only minimally improved (0.19 SDs).

Of the five domains in the EQ-5D instrument, depression mainly impacted the anxiety/depression, usual activities, and pain/discomfort domains. ${ }^{48}$ Our data found the same pattern in that $98.4 \%$ of our patients indicated problems in the anxiety/depression domain at baseline, followed by $85.7 \%$ and $60.6 \%$ of the patients who indicated problems in the usual activities and pain/discomfort domains, respectively. Conversion of the EQ-5D descriptive system to an index score translated into a baseline score of 0.56 (95\% CI: $0.53-0.58)$. Comparable values are reported in other studies described in Table 4 . At the end of acute treatment, we observed significant health gains. When we examined the index value scores of those patients in remission, there were larger health gains from baseline to end of treatment (range: $0.28-0.34, \mathrm{P}<0.0001$ ) compared to those experienced by patients who did not achieve remission (range: $0.11-0.12, \mathrm{P}<0.0001$ ).

Recent studies also demonstrate a correlation between depression and QOL. ${ }^{31-33,37,54,55}$ As mentioned previously, however, improvement in depressive symptoms may not accurately represent the overall treatment effect, and there are occasions when improvement in QOL lags behind symptomatic improvement. ${ }^{31}$ To assess whether acute TMS treatment is correlated with disease burden, we performed correlation analyses and found a strong association between improvement in depressive symptoms and QOL as assessed by both the SF-36 and EQ-5D measures (data not shown). This is an important observation, indicating that TMS treatment can induce an improvement in depression and well-being in a relatively short time-frame (ie, 6 weeks). By comparison, most studies of antidepressant medication were typically 8 weeks or longer in duration.

\section{Conclusion}

In summary, treatment-resistant depressed patients experienced improvement in functional status and QOL following acute TMS treatment, which appears comparable to those produced by antidepressant medications. Most notably, severely depressed patients experienced the most robust improvement in a relatively short time-frame. 
Table 4. Summary of studies examining the change in $E Q-5 D$ index score following antidepressant treatment

\begin{tabular}{|c|c|c|c|c|c|c|c|}
\hline Study & No. of patients and location & $\begin{array}{l}\text { Treatment or } \\
\text { outcome categories }\end{array}$ & Baseline & 4 weeks & 6 weeks & 8 weeks & $\geq 12$ weeks \\
\hline \multirow[t]{3}{*}{ Sapin, $2004^{56}$} & $\begin{array}{l}250 \text { new patients that were not } \\
\text { treated with antidepressants, France }\end{array}$ & Remitters & 0.35 & $0.76(+0.41)$ & & $0.85(+0.5)$ & \\
\hline & & Responders & 0.21 & $0.54(+0.33)$ & & $0.72(+0.51)$ & \\
\hline & & Non-responders & 0.3 & $0.54(+0.24)$ & & $0.58(+0.28)$ & \\
\hline \multirow[t]{3}{*}{ Peveler, $2005^{57}$} & $\begin{array}{l}327 \text { new patients that were not } \\
\text { treated with antidepressants, UK }\end{array}$ & $\mathrm{TCA}$ & 0.577 & $0.715(+0.138)$ & & $0.779(+0.202)$ & \\
\hline & & SSRIs & 0.608 & $0.726(+0.118)$ & & $0.775(+0.167)$ & \\
\hline & & Lofepramine & 0.574 & $0.674(+0.1)$ & & $0.753(+0.179)$ & \\
\hline \multirow[t]{4}{*}{ Sobocki, $2007^{48}$} & $\begin{array}{l}447 \text { new that were not treated } \\
\text { with antidepressants, Sweden }\end{array}$ & Total & 0.47 & $0.6(+0.13)$ & & & $0.69(+0.23)$ \\
\hline & & Mild (CGI-S) & 0.6 & & & & $0.76(+0.16)$ \\
\hline & & Moderate & 0.46 & & & & $0.69(+0.23)$ \\
\hline & & Severe & 0.27 & & & & $0.62(+0.16)$ \\
\hline \multirow[t]{5}{*}{ Mann, $2009^{37}$} & $\begin{array}{l}114 \text { patients treated with collabo- } \\
\text { rative care of medications and } \\
\text { psychological treatment, UK }\end{array}$ & Total & 0.516 & & & & $0.663(+0.147)$ \\
\hline & & Mild (PHQ-9) & 0.645 & & & & $0.826(+0.181)$ \\
\hline & & Moderate & 0.656 & & & & $0.706(+0.05)$ \\
\hline & & Moderately severe & 0.558 & & & & $0.388(-0.169)$ \\
\hline & & Severe & 0.337 & & & & $0.361(+0.024)$ \\
\hline \multirow[t]{5}{*}{ Carpenter, $2012^{21}$} & 307 pharmacoresistant patients, USA & Total & 0.56 & & $0.75(+0.18)$ & & \\
\hline & & None-Mild (PHQ-9) & 0.75 & & $0.87(+0.12)$ & & \\
\hline & & Moderate & 0.7 & & $0.81(+0.11)$ & & \\
\hline & & Moderately severe & 0.56 & & $0.72(+0.15)$ & & \\
\hline & & Severe & 0.47 & & $0.72(+0.24)$ & & \\
\hline
\end{tabular}

\section{Discloures}

Scott Aaronson has the following disclosures: Neuronetics, speaker's bureau, speakers fee; Genomind, consulting, consulting fee; Genomind, research support, research grant; Sunovion, speaker's bureau, speaker's fee. Dafna Bonneh-Barkay has the following disclosures: Neuronetics, employee, salary, stock options. Terrence Boyadjis has the following disclosures: Neuronetics, Inc., research support to the Institute of Pennsylvania (clinical trial), contract. David Brock has the following disclosures: Neuronetics, Inc. employee, salary, stock options. Ian Cook has the following disclosures: Covidien, consultant, consulting fees, research support, grant; Shire, research support, grant; Neuronetics, speaker's bureau, honoraria, research support, grant; Allergan, advisory board, consulting fee; Pfizer, advisory board, consulting fee; NeuroSigma, consultant, consulting fee, license of patents, stock options; NIH, research grant, grant, review committee, honoraria; VA, service on DSMB, honoraria. Linda Carpenter has the following disclosures: Neuronetics, research support to Butler, contract (clinical trial); Neosych, research support to Butler, contract (clinical trial); Corcept, consultant, honoraria; Takada/Lundbeck, consultant, consulting fee; Abbott, consultant, consulting fee; Johnson \& Johnson, consultant, honoraria; Metronic, research support to Butler, contract (clinical trial). David
Dunner has the following disclosures: Cyberonics, grant support, research support; Cervel, consultant, consultant fees; Neuronetics, grant support, research support, consultant, consultant fees; BristolMyersSquibb, consultant, consultant fees; Jazz, consultant, consultant fees. Mark Demitrack has the following disclosures: Neuronetics, Inc., employee, salary, stock options. Hugh Solvason has the following disclosures: Neuronetics, research support, research grant; St. Jude Medical, research support, research grant; Astrazeneca, research support, research grant; Roche, research support, research grant; Brain Resource, research support, research grant. Philip Janicak has the following disclosures: Cervel Neurotech, Inc., research support, grant; Janssen/OrthoMcNeil, research support, grant; Neuronetics, research support, grant, advisor, consultant; Novartis, research support, grant; Otsuka, research support, grant; The Research Foundation for Mental Hygiene, Inc., reserach support, grant; Karl Lanocha has the following disclosures: Neuronetics, research support, speaker's bureau.

\section{References}

1. Murray CJ, Lopez AD. Alternative projections of mortality and disability by cause 1990-2020: Global Burden of Disease Study. Lancet. 1997; 349: 1498-1504. 
2. Murray C, Lopez AD. Evidence-based health policy-lessons from the Global Burden of Disease Study. Science. 1996; 274(5288): 740-743.

3. Greenberg PE, Kessler RC, Birnbaum HG, et al. The economic burden of depression in the United States: how did it change between 1990 and 2000? J Clin Psychiatry. 2003; 64: 1465-1475.

4. Sackeim HA. The definition and meaning of treatmentresistant depression. J Clin Psychiatry. 2001; 62: 10-17.

5. Rush AJ, Thase ME, Dubé S. Research issues in the study of difficult-to-treat depression. Biol Psychiatry. 2003; 53: 743-753.

6. Janicak PG, Marder S, Pavuluri M. Principles and Practice of Psychopharmacotherapy, 5th ed. Philadelphia, PA: Lippincott Williams \& Wilkins; 2011: 256-263.

7. Fava M, Rush AJ, Trivedi M, et al. Background and rationale for the sequenced treatment alternatives to relieve depression (STAR*D) study. Psychiatr Clin North Am. 2003; 26: 457-494.

8. Rush AJ, Fava M, Wisniewski SR, et al. Sequenced treatment alternatives to relieve depression (STAR*D): rationale and design. Control Clin Trials. 2004; 25: 119-142.

9. Trivedi MH, Rush AJ, Wisniewski SR, et al. Evaluation of outcomes with citalopram for depression using measurement-based care in STAR*D implications for clinical practice. Am J Psychiatry. 2006; 163: 28-40.

10. Rush AJ, Trivedi MH, Wisniewski SR, et al. Bupropion-SR, sertraline, or venlafaxine-XR after failure of SSRIs for depression. N Engl J Med. 2006; 354: 1231-1242.

11. Fava M, Rush AJ, Wisniewski SR, et al. A comparison of mirtazapine and nortriptyline following two consecutive failed medication treatments for depressed outpatients: A STAR*D report. Am J Psychiatry. 2006; 163: 1161-1172.

12. McGrath PJ, Stewart JW, Fava M, et al. Tranylcypromine versus venlafaxine plus mirtazapine following three failed antidepressant medication trials for depression: a STAR*D report. Am J Psychiatry. 2006; 163: 1531-1541.

13. Nierenberg AA, Fava M, Trivedi $\mathrm{MH}$, et al. A comparison of lithium and $\mathrm{T}_{3}$ augmentation following two failed medication treatments for depression: a STAR*D report. Am J Psychiatry. 2006; 163: 1519-1530.

14. Rush AJ, Trivedi MH, Wisniewski SR, et al. Acute and longer-term outcomes in depressed outpatients requiring one or several treatment steps: a STAR*D report. Am J Psychiatry. 2006; 163: 1905-1917.

15. Janicak P, O'Reardon JP, Sampson SM, et al. Transcranial magnetic stimulation in the treatment of major depressive disorder: a comprehensive summary of safety experience from acute exposure, extended exposure, and during reintroduction treatment. J Clin Psychiatry. 2008; 69: 222-232.

16. Janicak PG, Nahas Z, Lisanby SH, et al. Durability of clinical benefit with transcranial magnetic stimulation (TMS) in the treatment of pharmacoresistant major depression: assessment of relapse during a 6-month, multisite, open-label study. Brain Stimul. 2010; 3: 187-199.
17. George MS, Lisanby SH, Avery D, et al. Daily left prefrontal transcranial magnetic stimulation therapy for major depressive disorder: a sham-controlled randomized trial. Arch Gen Psychiatry. 2010; 67: 507-516.

18. Avery DH, Isenberg KE, Sampson SM, et al. Transcranial magnetic stimulation in the acute treatment of major depressive disorder: clincical response in an open-label extension trial. J Clin Psychiatry. 2008; 69: 441-451.

19. O'Reardon JP, Solvason HB, Janicak PG, et al. Efficacy and safety of transcranial magnetic stimulation in the acute treatment of major depression: a multisite randomized controlled trial. Biol Psychiatry. 2007; 62: 1208-1216.

20. Demitrack MA, Thase M. Clinical significance of transcranial magnetic stimulation (TMS) in the treatment of pharmacoresistant depression: synthesis of recent data. Psychopharmacol Bull. 2009; 42: 5-38.

21. Carpenter LL, Janicak PG, Aaronson ST, et al. Transcranial magnetic stimulation (TMS) for major depression: a multisite, naturalistic, observational study of acute treatment outcomes in clinical practice. Depress Anxiety. 2012; 29(7): 587-596.

22. Connolly KR, Helmer A, Cristancho MA, et al. Effectiveness of transcranial magnetic stimulation in clinical practice post-FDA approval in the United States: results observed with the first 100 consecutive cases of depression at an academic medical center. J Clin Psychiatry. 2012; 73(4): e567-e573.

23. Shafi MM, Westover MB, Fox MD, et al. Exploration and modulation of brain network interactions with noninvasive brain stimulation in combination with neuroimaging. Eur J Neurosci. 2012; 35(6): 805-825.

24. Pascual-Leone A, Tormos JM, Keenan J, et al. Study and modulation of human cortical excitability with transcranial magnetic stimulation. J Clin Neurophysiol. 1998; 15: 333-343.

25. Wells KB, Stewart A, Hays RD, et al. The functioning and well-being of depressed patients-results from the medical outcomes study. JAMA. 1989; 262: 914-919.

26. Broadhead WE, Blazer DG, George LK, et al. Depression, disability days, and days lost from work in a prospective epidemiologic survey. JAMA. 1990; 264: 2524-2528.

27. Kennedy N, Foy K, Sherazi R, et al. Long-term social functioning after depression treated by psychiatrists: a review. Bipolar Disord. 2007; 9: 25-37.

28. Fairclough DL. Design and Analysis of Quality of Life Studies in Clinical Trials. Boca Raton, FL: Chapman and Hall/CRC; 2002.

29. Fayers PM. Quality of Life: Assessment, Analysis and Interpretation. West Sussex, UK: Wiley; 2002.

30. Judd LL, Akiskal HS, Zeller PJ, et al. Psychosocial disability during the long-term course of unipolar major depressive disorder. Arch Gen Psychiatry. 2000; 57: 375-380.

31. Trivedi MH, Rush AJ, Wisniewski SR, et al. Factors associated with health-related quality of life among outpatients with major depressive disorder: a STAR*D report. J Clin Psychiatry. 2006; 67(2): 185-195. 
32. Wisniewski SR, Rush AJ, Bryan C, et al. Comparison of quality of life measures in a depressed population. J Nerv Ment Dis. 2007; 195(3): 219-225.

33. McCall WV, Rosenquist PB, Kimball J, et al. Healthrelated quality of life in a clinical trial of ECT followed by continuation pharmacotherapy: effects immediately after ECT and at 24 weeks. J ECT. 2011; 27: 97-102.

34. Solomon DA, Leon AC, Coryell W, et al. Predicting recovery from episodes of major depression. J Affect Disord. 2008; 107: 285-291.

35. Ware JE Jr, Sherbourne CD. The MOS 36-item short-form health survey (SF-36). I. Conceptual framework and item selection. Med Care. 1992; 30: 473-483.

36. Brooks R. EuroQol: the current state of play. Health Policy. 1996; 37: 53-72.

37. Mann R, Gilbody S, Richards D. Putting the " $\mathrm{Q}$ " in depression QALYs: a comparison of utility measurement using EQ-5D and SF-6D health related quality of life measures. Soc Psychiatry Psychiatr Epidemiol. 2009; 44(7): 569-578.

38. Ware JE Jr, Kosinski M, Gandek B. SF-36 Health Survey: Manual and Interpretation Guide. Lincoln, RI: QualityMetric Incorporated, 1993, 2000.

39. www.euroqol.org.

40. http://www.ahrq.gov/rice/EQ5Dscore.htm\#weights.

41. Macran S, Kind P. "Death" and the valuation of healthrelated quality of life. Medical Care. 2001; 39(3): 217-227.

42. Katzelnick DJ, Duffy FF, Chung H, et al. Depression outcomes in psychiatric clinical practice: using a selfrated measure of depression severity. Psychiatr Serv. 2011; 62(8): 929-935.

43. Cui Z, Faries DE, Gelwicks S, Novick D, Liu X. Early discontinuation and suboptimal dosing of duloxetine treatment in patients with major depressive disorder: analysis from a US third-party payer perspective. J Med Econ. 2012; 15: 134-144.

44. Hardeveld F, Spijker J, De Graaf R, Nolen WA, Beekman AT. Prevalence and predictors of recurrence of major depressive disorder in the adult population. Acta Psychiatr Scand. 2010; 122: 184-191.

45. Ware JE Jr, Kosinski M. SF-36 Physical \& Mental Health Summary Scales: A Manual for Users of Version 1, 2nd ed. Lincoln, RI: QualityMetric Incorporated; 2001.

46. Dunner DL, Rush AJ, Russell JM, et al. Prospective, long-term, multicenter study of the naturalistic outcomes of patients with treatment-resistant depression. J Clin Psychiatry. 2006; 67: 688-695.

47. Gunther $\mathrm{OH}$, Roick $\mathrm{C}$, Angermeyer $\mathrm{MC}$, et al. The responsiveness of EQ-5D utility scores in patients with depression: a comparison with instruments measuring quality of life, psychopathology and social functioning. J Affect Disord. 2007; 105: 81-91.

48. Sobocki $\mathrm{P}$, Ekman M, Agren $\mathrm{H}$, et al. Health-related quality of life measured with EQ-5D in patients treated for depression in primary care. Value Health. 2007; 10: 153-160.

49. Simon GE, Revicki DA, Grothaus L, et al. SF-36 summary scores: are physical and mental health truly distinct? Med Care. 1998; 36: 567-572.

50. Garcia-Cebrian A, Bauer M, Montejo AL, et al. Factors influencing depression endpoints research (FINDER): study design and population characteristics. Eur Psychiatry. 2008; 23: 57-65.

51. Walker V, Streiner DL, Novosel S, et al. Health-related quality of life in patients with major depression who are treated with moclobemide. J Clin Psychopharmacol. 1995; 15: 60S-67S.

52. Reed C, Monz BU, Perahia DG, et al. Quality of life outcomes among patients with depression after 6 months of starting treatment: results from FINDER. J Affect Disord. 2009; 113: 296-302.

53. Kroenke K, West SL, Swindle R, et al. Similar effectiveness of paroxetine, fluoxetine, and sertraline in primary care. JAMA. 2001; 286: 2947-2955.

54. Yatham LN, Lecrubier Y, Fieve RR, et al. Quality of life in patients with bipolar I depression: data from 920 patients. Bipolar Disord. 2004; 6(5): 379-385.

55. ten Doesschate MC, Koeter MWJ, Bockting CLH, et al. Health related quality of life in recurrent depression: a comparison with a general population sample. J Affect Disord. 2010; 120(1-3): 126-132.

56. Sapin C, Fantino B, Nowicki ML, Kind P. Usefulness of EQ-5D in assessing health status in primary care patients with major depressive disorder. Health Qual Life Outcomes. 2004; 2: 20.

57. Peveler R, Kendrick T, Buxton M, et al. A randomised controlled trial to compare the cost-effectiveness of tricyclic antidepressants, selective serotonin reuptake inhibitors and lofepramine. Health Technol Assess. 2005; 9(16): 1-134. 